\title{
Recurrent Epithelioid Sarcoma
}

National Cancer Institute

\section{Source}

National Cancer Institute. Recurrent Epithelioid Sarcoma. NCI Thesaurus. Code C5059.

The reemergence of epithelioid sarcoma after a period of remission 